\title{
A genome-wide scan for genes involved in primary vesicoureteric reflux
}

\author{
H Kelly, C M Molony, J M Darlow, M E Pirker, A Yoneda, \\ A J Green, P Puri, D E Barton
}

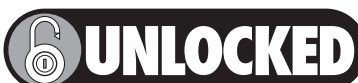

This paper is freely available online under the BMJ Journals unlocked scheme, see http://img.bmi.com/info/unlocked.dtl
See end of article for authors' affiliations

Correspondence to:
David E Barton, The
National Centre for Medical
Genetics, Our Lady's
Children's Hospital Crumlin
Dublin 12, Ireland;
david.barton@olchc.ie
Received 17 April 2007
Revised 19 June 2007
Accepted 11 July 2007
Published Online First
27 July 2007
..........................

Background: Vesicoureteric reflux (VUR) is the retrograde flow of urine from the bladder into the ureters. It is the most common urological anomaly in children, and a major cause of end-stage renal failure and hypertension in both children and adults. VUR is seen in approximately $1-2 \%$ of Caucasian newborns and is frequently familial.

Objective and methods: In order to search for genetic loci involved in VUR, we performed a genome-wide linkage scan using 4710 single-nucleotide polymorphisms (SNPs) in 609 individuals from 129 Irish families with $>1$ affected member.

Results: Nonparametric linkage (NPL) analysis of the dataset yielded moderately suggestive linkage at chromosome $2 q 37\left(N L_{\max }=2.67, p<0.001\right)$. Analysis of a subset without any additional features, such as duplex kidneys, yielded a maximum NPL score of $4.1(p=0.001)$, reaching levels of genome-wide statistical significance. Suggestive linkage was also seen at 10q26 and 6q27, and there were several smaller peaks. Conclusion: Our results confirm the previous conclusion that VUR is genetically heterogeneous, and support the identification of several disease-associated regions indicated by smaller studies, as well as indicating new regions of interest for investigation.
$\mathrm{V}$ esicoureteric reflux (VUR, OMIM 193000) is the retrograde flow of urine from the bladder along the ureter towards the kidneys. VUR is common, occurring in an estimated $1-2 \%$ of Caucasian newborns ${ }^{1}$ and is a major cause of end-stage renal failure and hypertension in both children and adults. ${ }^{1-3}$ An estimated $30-50 \%$ of children presenting with urinary tract infections (UTI) have VUR ${ }^{4}$ and the reflux of infected urine can cause pyelonephritis and resultant permanent renal damage. Anatomically, primary vesicoureteric reflux arises from a submucosal ureter that is of insufficient length, or a ureteric orifice that is too wide to allow for the operation of a proper valvular mechanism. ${ }^{13}$ VUR occurs frequently in families; approximately half of the offspring will be affected but the mode of inheritance is unknown. ${ }^{1}$ Micturating cystourethrography (MCUG) in children may be performed because of UTI or suspicion of renal-tract anomalies from prenatal ultrasonography, and in either case both VUR and renal tract anomalies, including duplex renal systems, are commonly found. ${ }^{56}$ Furthermore, VUR is more common in those with duplex than with single renal tracts, and duplex kidneys are commonly found in those with VUR. ${ }^{67}$ In both mice and humans, individuals with various renal tract defects, including VUR, occur in the same sibships, indicating that mutations of the same genes can cause both renal developmental anomalies and VUR, with considerable phenotypic variation, for reasons yet to be identified. ${ }^{3} 89$

To date, the only genes identified as mutated in VUR have been in cases with other anomalies, or in families in which other anomalies were segregating. Hu et al observed VUR among other features in mice in which the gene for uroplakin III (locus $U P K 3 A$ ) had been homozygously inactivated. ${ }^{10}$ Linkage $^{11}$ and mutation screening studies ${ }^{12}$ of UPK $3 A$ and other members of the uroplakin family ${ }^{13}{ }^{14}$ (Kelly et al, unpublished data) in humans did not show evidence for their involvement in VUR, but mutations in UPK3A have now been found in some cases of renal aplasia, hypoplasia and dysplasia, including some with VUR. ${ }^{15}{ }^{16}$ The PAX2 gene has been shown to be mutated in renal-coloboma syndrome, which includes VUR as part of a complex phenotype, ${ }^{17}{ }^{18}$ and in renal hypoplasia and VUR without eye defects, ${ }^{19}$ but has not been found to be mutated in uncomplicated VUR.$^{20}$ Investigation of a patient with multiple congenital anomalies, including severe bilateral VUR, found a Y;3 translocation that disrupted $\mathrm{ROBO2}$, and investigation of this gene in 124 families with VUR with potential autosomal dominance revealed mutations in two families. $^{21}$ Both index cases had bilateral VUR (one having hypoplastic kidneys and nephropathy, the other having a unilateral duplex system), and most affected relatives in both families had renal anomalies. Inheritance in all of the above cases appeared to be autosomal dominant, but mutations in these genes account for a very small proportion of VUR in general.

Attempts at mapping other genes for VUR have included genome-wide scans of small numbers of multi-generation families $^{22}{ }^{23}$ (the latter yet to be reported in full), or individual or small collections of cases with chromosomal rearrangements, ${ }^{24-27}$ although most patients in the latter group also had other renal tract anomalies. These studies identified several possible loci, and indicated that the disease is genetically heterogeneous. Several candidate-gene studies to confirm some of these and other loci possibly involved in VUR have been unsuccessful. ${ }^{28-30}$

In this paper, we present the results of a genome-wide linkage scan with 4710 SNP markers and 129 families, each with $\geqslant 2$ individuals who meet the criteria for a diagnosis of primary VUR.

\section{METHODS \\ Subjects}

The samples for this study were collected at Our Lady's Children's Hospital Crumlin, and the National Children's

Abbreviations: HLOD, heterogeneity logarithm of odds; OMIM, Online Mendelian Inheritance in Man; MCUG, micturating cystourethrography; NPL, nonparametric linkage; SNP, single-nucleotide polymorphism; TDT, transmission disequilibrium test; UTI, urinary tract infections; VUR, vesicoureteric reflux 

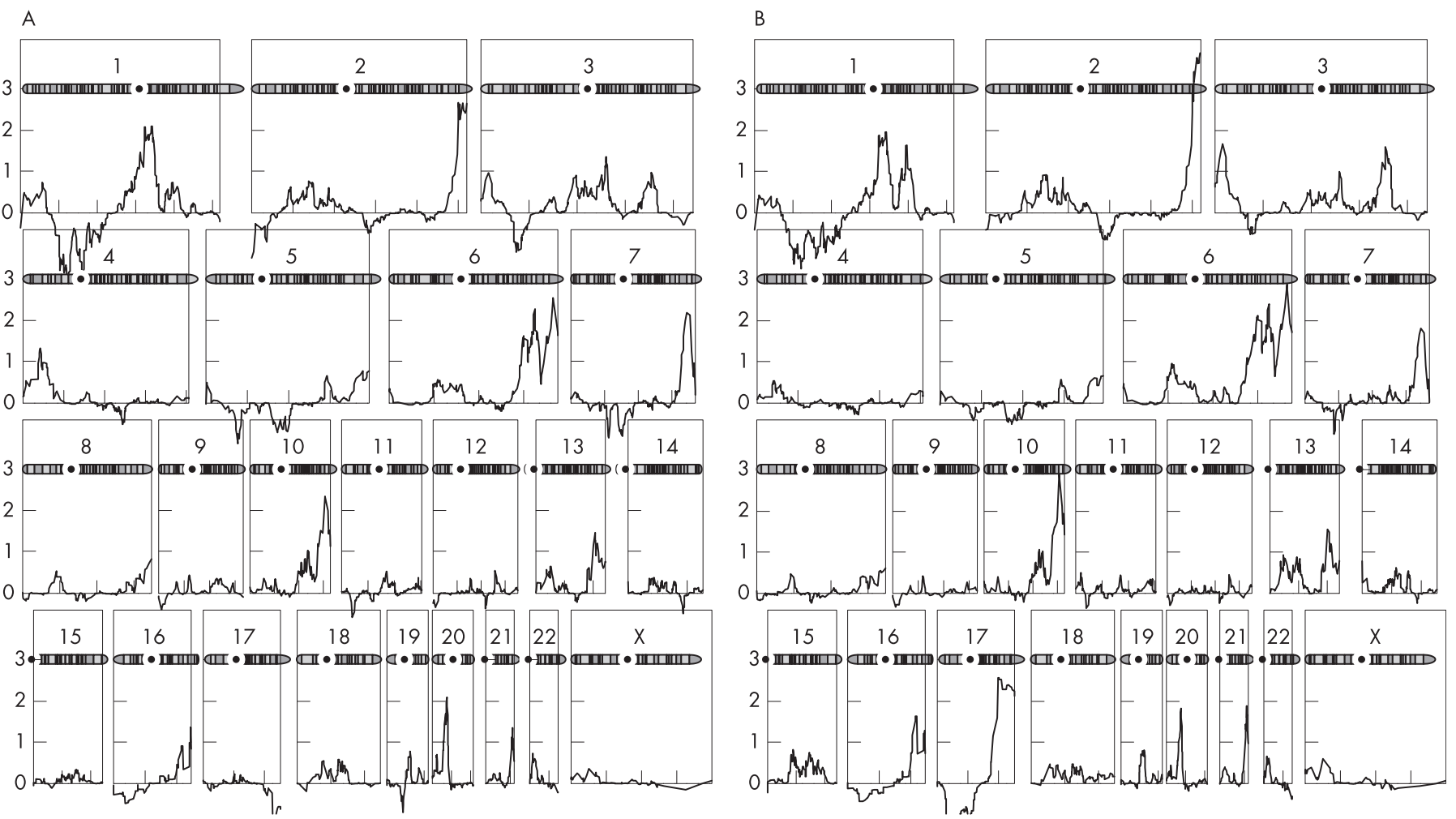

Figure 1 Layout plots of nonparametric linkage (NPL) scores from the genome scan. (A) Full dataset; (B) uncomplicated dataset. The vertical axis shows NPL scores. Plots are scaled vertically to show the maximum peak (4.10) in the uncomplicated dataset.

Hospital, Tallaght, both in Dublin, Ireland. Ethics approval was granted, and informed consent was obtained from all subjects and/or their parents. Families with $\geqslant 2$ affected siblings with primary VUR of any grade were collected. All families are Caucasian and the majority considered to be of homogeneous Irish ancestry. All index cases were referred because of recurrent UTIs and diagnosed by MCUG. Siblings of index cases were screened by MCUG. Three parents and one grandparent of affected children were classed as affected because they had been diagnosed with primary VUR in the past; others with merely a history of renal problems were classified as of unknown affectedness status. Patients with VUR secondary to other conditions were not collected. Note: most authors agree that secondary VUR can result from bladder dysfunction (neurogenic bladder and non-neurogenic neurogenic bladder (Hinman-Allen syndrome)), posterior urethral valves, or ureterocoele, $^{31}$ but some authors include complete duplex renal systems as a cause, ${ }^{32}$ and some count some cases with duplex systems as primary and some as secondary. ${ }^{33}$ All families included in our study were considered to exhibit primary VUR. It was noted that in one of the excluded families, only one of the affected members had a posterior urethral valve, and in one of the included families, one of the affected members had a ureterocoele. From a developmental genetics point of view, both types of condition could probably safely be included (see Introduction and Discussion).

\section{Genotyping}

Samples were sent to Illumina (San Diego, California, USA) for genotyping. The panel (linkage panel III) consisted of 4753 SNP markers, with an average distance between markers of $600 \mathrm{~Kb}$.

In total, 626 DNA samples from 133 families were genotyped, but 4 families were subsequently removed because exclusion of members giving non-mendelian results left only one affected member. The following figures for the remaining 129 families refer only to genotyped individuals. They included 255 parents ( 3 affected, 5 unaffected, and 247 with unknown affectedness status), 283 affected siblings (117 male and 166 female), 37 unaffected siblings ( 17 male and 20 female), 32 siblings with unknown affectedness status ( 14 male and 18 female) and 2 grandparents (one affected and one of unknown status). There were 107 families with 2 genotyped affected children, 20 with 3 , 1 with 4 and 1 with 5, giving 183 affected sibling pairs in total.

Six samples gave no genotype results, thus 638 samples $(620$ samples +18 replicates) were genotyped in total. After cleaning the data for mendelian errors and departures from HardyWeinberg equilbrium (ie removing obvious genotyping errors) with Pedstats software, ${ }^{34} 4710$ SNPs were used in the analysis. Of the possible 3004980 genotypes, 3002877 were reported, giving a success rate of $99.93 \%$. The mean heterozygosity over all markers was $46.1 \%$.

\section{Statistical analysis}

Both non-parametric and parametric linkage analysis for the scan was performed using MERLIN V.1.0.1.10.3 (http:// www.sph.umich.edu/csg/abecasis/Merlin). ${ }^{34}{ }^{35}$ NPL scores were based on a procedure for converting scores for individual inheritance vectors into $\mathrm{Z}$ scores for single or multiple pedigrees, ${ }^{36}$ which are used to construct a likelihood ratio test for linkage and define a (NPL) LOD score statistic. ${ }^{37}$ The dataset was prepared for analysis using MEGA2 software (http:// www.megasoftware.net/ $)^{38}$ and markers in tight $\mathrm{LD}\left(\mathrm{D}^{\prime}>0.7\right)$ were removed from the dataset prior to analysis using the SNPLINK program (http://www.icr.ac.uk/research/research sections/cancer genetics/cancer genetics teams/molecular and population_genetics/software_and_databases/index.shtml $)^{\overline{39}}$ The resultant panel consisted of 3861 markers. Although all patients included in the study had primary VUR, 25 families included patients with additional phenotypic features. These features were mainly duplex kidneys ( 20 families, in most of which only one of 
Table 1 Linkage results: regions showing suggestive evidence of linkage in the full dataset

\begin{tabular}{|c|c|c|c|c|c|c|c|c|}
\hline \multirow[b]{2}{*}{ Location } & \multicolumn{2}{|c|}{ SNP markers } & \multirow{2}{*}{$\begin{array}{l}\text { Interval } \\
\text { (cM) }\end{array}$} & \multirow{2}{*}{$\begin{array}{l}\text { Interval } \\
(\text { Mbp) })^{*}\end{array}$} & \multirow{2}{*}{$\begin{array}{l}\text { Width } \\
\text { (Mbp) }\end{array}$} & \multirow[b]{2}{*}{ LOD } & \multirow{2}{*}{$\begin{array}{l}\text { Maximum } \\
\text { NPL }\end{array}$} & \multirow[b]{2}{*}{ p Value } \\
\hline & 1 & 2 & & & & & & \\
\hline $1 q 23.2-q 25.2$ & rs1053074 & rs 1923626 & $152-175$ & $158.3-175.3$ & 17.05 & -18.10 & 2.10 & $1 \times 10^{-4}$ \\
\hline $2 q 37.2-q 37.3$ & rs869214 & rs 16747 & $246-261$ & $235.6-242.4$ & 6.79 & -15.33 & 2.67 & $2 \times 10^{-4}$ \\
\hline $3 p 13-q 21.2$ & rs7064 & rs713161 & $96-131$ & $126.3-127.4$ & 1.1 & -17.36 & 1.36 & $6 \times 10^{-3}$ \\
\hline $3 q 26.31$ & rs2046718 & rs753293 & $177-178$ & $175.0-176.6$ & 1.6 & -20.8 & 0.98 & 0.02 \\
\hline $4 p 16.1-p 15.31$ & rs 1981635 & rs729918 & $18-30$ & $10.2-20.1$ & 9.9 & -19.77 & 1.33 & $7 \times 10^{-3}$ \\
\hline $6 q 24.1-q 27$ & rs1931992 & rs756519 & $146-188$ & $142.6-170.7$ & 28.1 & -9.16 & 2.55 & $3 \times 10^{-4}$ \\
\hline $7 q 36.1-q 36.3$ & rs1547958 & rs 1343750 & $165-179$ & $150.3-155.2$ & 4.94 & -14.94 & 2.19 & $7 \times 10^{-4}$ \\
\hline $10 \mathrm{q} 25.2-\mathrm{q} 26.3$ & rs1327551 & rs 880340 & $120-165$ & $112.8-134.9$ & 22.1 & -11.38 & 2.35 & $5 \times 10^{-4}$ \\
\hline $13 q 33.2-q 33.3$ & rs 981900 & rs 1876723 & $100-108$ & $105.3-107.4$ & 2.12 & -15.17 & 1.47 & $5 \times 10^{-3}$ \\
\hline $16 q 24.1-q 24.3$ & rs 454087 & rs8577 & $107-123$ & $83.1-88.6$ & 5.5 & -4.02 & 1.36 & $7 \times 10^{-3}$ \\
\hline 20 p12.2-p11.23 & rs742920 & rs761461 & $30-41$ & $11.0-18.2$ & 7.25 & -17.73 & 2.09 & $1 \times 10^{-3}$ \\
\hline $21 q 22.3$ & rs234705 & rs235310 & $53-56$ & $42.8-45.1$ & 2.3 & -25.69 & 1.35 & $6 \times 10^{-3}$ \\
\hline
\end{tabular}

LOD, logarithm of odds; NPL, nonparametric linkage.

*Estimated by closest reported marker.

the patients with VUR had a duplex system) but also included fused kidneys, renal hypoplasia, large ureterocoele, branchial cleft remnants, or mental retardation with abnormal facies. After the initial scan, these families were removed to create a subset for further analysis. The reduced set consisted of 104 families, comprising 480 members.

A genetic model of inheritance for VUR has been proposed both in segregation studies ${ }^{40}$ and in studies of large multigenerational families. ${ }^{22}$ A single model was tested in the parametric analysis, which corresponded to an autosomal dominant mode of inheritance with a disease frequency of 0.01 and incomplete penetrance according to the previously proposed genetic model. ${ }^{40}$ Power for the complete cohort is estimated to be $\sim 79 \%(\alpha=0.05)$, given the genetic model, a common test marker allele frequency and $\theta=0.1$. This is likely to be an overestimate in general, as power will have fluctuated substantially based on marker and multimarker informativeness, increasing $\theta$, or the sample size reduction, as in our uncomplicated cohort setting. For parametric analysis, heterogeneity was investigated using the heterogeneity logarithm of odds (HLOD) statistic. Abreu et al ${ }^{41}$ suggest that an HLOD of approximately 1.2 for a fully penetrant autosomal dominant genetic model corresponds to a p value of 0.01 and results exceeding this level are reported for exploratory purposes, as these parameters are rough approximations of a genetic model of VUR. Stringent criteria for statistical significance of genomewide scans were used, based on previously published guidelines: ${ }^{42} \mathrm{p}<0.001$ and a LOD score of $2.2(\mathrm{NPL}=3.18)$ was suggestive of linkage, and $\mathrm{p}<0.001$ and a LOD score of 3.6 $(\mathrm{NPL}=4.08)$ was considered significant linkage. ${ }^{42}$ All regions

\begin{tabular}{llll}
\multicolumn{3}{l}{$\begin{array}{l}\text { Table } 2 \\
\text { for complete dataset }\end{array}$} & $\begin{array}{l}\text { Heterogeneity logarithm of odds scores } \\
\text { Chromosome }\end{array}$ \\
\hline 1 & cM & HLOD & $\alpha$ \\
\hline 2 & 169 & 1.45 & 0.29 \\
3 & 260 & 2.90 & 0.40 \\
4 & 129 & 1.55 & 0.29 \\
5 & 21 & 1.64 & 0.29 \\
6 & 145 & 1.31 & 0.25 \\
7 & 163 & 3.55 & 0.42 \\
10 & 172 & 1.84 & 0.33 \\
13 & 154 & 1.78 & 0.36 \\
20 & 104 & 1.37 & 0.29 \\
& 38 & 1.25 & 0.29
\end{tabular}

All areas giving heterogeneity logarithm of odds (HLOD) scores $>1.2$ are reported. with $\mathrm{p} \leqslant 0.02(\mathrm{NPL}=\sim 0.9)$ in the nonparametric analysis were reported and used to define linkage peak intervals. Regions with NPL $>2.00$ were also highlighted in the results as potentially interesting. Exploratory analysis of association in the linkage panel was performed using the transmission disequilibrium test (TDT) using the discrete trait testing option for general pedigrees in the QTDT program (http://www.sph. umich.edu/csg/abecasis/QTDT/). ${ }^{43}$

\section{RESULTS}

Tables 1 and 2 show the results of the genome-wide linkage analysis based on the full set of 129 families. Under genetic homogeneity, all parametric multipoint LOD scores were negative, thus rejecting support for linkage under the model used for the complete sample (table 1). However, positive HLOD scores allowing for heterogeneity indicated that a subset of families might be informative under this model and showed linkage that was suggestive in 10 regions across the genome (table 2 ). The proportion of linked families $(\alpha)$ was estimated as approximately one-third of the sample for each of these regions, and the remaining families must reject linkage of these regions based on the strong negative parametric LOD scores as noted above. NPL analysis yielded six regions that are potentially interesting candidate regions based on their NPL scores under standard criteria ${ }^{42}$ (fig lA, table 1). All of these regions were coincident with regions that exhibited evidence of heterogeneity (HLOD >1.2) under the parametric analysis (table 2). In addition to these six regions, six additional regions in the nonparametric scan provided NPL scores that exceeded the less stringent threshold of $p<0.02$, three of which were also coincident with regions showing heterogeneity (tables 1 and 2).

The subset of samples we termed the uncomplicated set (UCS), defined by excluding the 25 families in which some affected members had additional phenotypic features, was also analysed to see whether this resulted in stronger linkage support. Greater support for the existence of linkage was provided from the UCS in both the parametric analysis under heterogeneity and nonparametric analyses. NPL analysis yielded a maximum NPL score of $4.1(\mathrm{p}<0.001)$ at $2 \mathrm{q} 37$, reaching levels of genome-wide statistical significance, ${ }^{42}$ It also identified other potentially interesting loci at 10q26 and 6q27, and nine additional candidate regions on eight different chromosomes with $\mathrm{p}<0.02$ (table 3, fig $1 \mathrm{~B}$ ); however, the most significant of these, (on 17q) was neither supported by the parametric analysis (table 4) nor seen at all in the full set.

Under the proposed genetic model, parametric analysis of the UCS provided a number of regions with only moderately negative LOD scores, in contrast to the strongly negative LOD 
Table 3 Regions showing evidence or suggestive evidence of linkage in the uncomplicated dataset

\begin{tabular}{|c|c|c|c|c|c|c|c|c|}
\hline \multirow[b]{2}{*}{ Location } & \multicolumn{2}{|l|}{ SNP markers } & \multirow[b]{2}{*}{$\begin{array}{l}\text { Interval } \\
\text { (cM) }\end{array}$} & \multirow[b]{2}{*}{$\begin{array}{l}\text { Interval } \\
\left(\text { Mbp) }{ }^{*}\right.\end{array}$} & \multirow[b]{2}{*}{$\begin{array}{l}\text { Width } \\
\text { (Mbp) }\end{array}$} & \multirow[b]{2}{*}{ LOD } & \multirow[b]{2}{*}{$\begin{array}{l}\text { Maximum } \\
\text { NPL }\end{array}$} & \multirow[b]{2}{*}{ p Value } \\
\hline & 1 & 2 & & & & & & \\
\hline $1 q 23.3-q 32.2$ & rs968853 & rs946125 & $161-203$ & $163.4-208.6$ & 41.4 & -14.17 & 1.96 & $1 \times 10^{-3}$ \\
\hline $2 q 37.1-q 37.3$ & rs 887062 & rs 16747 & $243-261$ & $234.4-242.4$ & 8.0 & -3.99 & 4.10 & $<1 \times 10^{-5}$ \\
\hline $3 p 26.3-p 26.2$ & rs 1499260 & rs902982 & $3-12$ & $1.6-4.6$ & 3.1 & -14.28 & 1.67 & $3 \times 10^{-3}$ \\
\hline $3 q 26.31-q 26.32$ & rs 1563436 & rs 1489630 & $174-181$ & $173.3-179.3$ & 6.0 & -10.39 & 1.60 & $3.1 \times 10^{-3}$ \\
\hline $6 q 23.3-q 27$ & rs 1041480 & rs756519 & $137-188$ & $135.4-170.7$ & 35.3 & -2.88 & 2.65 & $2 \times 10^{-4}$ \\
\hline $7 q 36.1-q 36.3$ & rs 1547958 & rs 1343750 & $164-179$ & $150.3-155.2$ & 4.9 & -10.88 & 1.81 & $2 \times 10^{-3}$ \\
\hline $10 \mathrm{q} 25.2-\mathrm{q} 26.3$ & rs 1050755 & rs 880340 & $119-165$ & $112.0-134.9$ & 22.9 & -3.89 & 2.89 & $1.3 \times 10^{-4}$ \\
\hline $13 q 33.2-q 33.3$ & rs981900 & rs 1876723 & $100-107$ & $105.3-107.4$ & 2.1 & -12.02 & 1.55 & $4 \times 10^{-3}$ \\
\hline $16 q 23.3-q 24.3$ & rs967955 & rs 1006547 & $102-122$ & $80.7-88.4$ & 7.7 & -1.38 & 1.63 & $3 \times 10^{-3}$ \\
\hline $17 q 24.2-q 25.3$ & rs 755424 & rs733342 & $91-126$ & $64.3-78.4$ & 14.1 & -3.31 & 2.56 & $3 \times 10^{-4}$ \\
\hline 20 p12.2-p12.1 & rs 803880 & rs727472 & $32-41$ & $11.8-17.3$ & 5.5 & -12.58 & 1.66 & $3 \times 10^{-3}$ \\
\hline $21 \mathrm{q} 22.3$ & rs876498 & rs 2256207 & $52-58$ & $42.7-46.9$ & 4.2 & -18.16 & 1.73 & $2 \times 10^{-3}$ \\
\hline
\end{tabular}

LOD, logarithm of odds; NPL, nonparametric linkage.

*See table 1.

scores obtained across the entire genome observed in the parametric analysis of the full set. Some of the regions, where the degree of "rejection" decreased in the UCS versus the FS parametric analysis, overlapped with some of those highlighted in the nonparametric analysis (tables 1 and 3).

Again, significant HLOD scores were coincident with significant or suggestive NPL scores, with HLODs of 3.37 and 3.28 for $2 \mathrm{q} 37$ and $6 \mathrm{q} 27$, respectively. As the overall number of families decreased, the proportion of linked families increased to as much as 0.5 in these regions (table 4); elsewhere, there were more modest changes. Individual familial LOD scores were obtained; it seemed from these that there was no significant enrichment or association for uncomplicated status and individual family contributions to linkage (familial LOD score $>0$ ) (Fisher's exact test $\mathrm{p}>0.05$ in both of these regions). Thus, any increase in linkage signal or change in support for a particular region was probably a reflection of the changes in study population composition, combined with the removal of families that, by chance, might have previously strongly rejected linkage in these regions. It appears that there remains significant genetic heterogeneity in this VUR population, and that the inclusion of cases with additional phenotypic features cannot explain fully the observed statistics. Although the evidence for linkage in the uncomplicated set appeared to be stronger, the regions highlighted covered greater segments of the genome (the mean interval of the significant nonparametric regions was $12.9 \mathrm{Mb}$ ).

Additional exploratory association testing using the TDT gave no significant results after correction for multiple testing. None of the most significant association results $(p<0.01)$ before correction were located in the regions supported by the linkage analysis.

\begin{tabular}{|c|c|c|c|}
\hline Chromosome & $c M$ & HLOD & $\alpha$ \\
\hline 1 & 168 & 1.30 & 0.31 \\
\hline 2 & 260 & 3.37 & 0.50 \\
\hline 3 & 177 & 1.40 & 0.34 \\
\hline 6 & 163 & 3.28 & 0.45 \\
\hline 7 & 172 & 1.37 & 0.34 \\
\hline 10 & 154 & 2.19 & 0.48 \\
\hline 13 & 23.2 & 1.32 & 0.30 \\
\hline 20 & 38 & 1.36 & 0.32 \\
\hline
\end{tabular}

HLOD, heterogeneity logarithm of odds.

\section{DISCUSSION}

This is by far the largest linkage study of VUR yet undertaken, in terms both of families and markers tested. The results from the scan revealed 10-15 regions of varying sizes and levels of support or significance across the genome. It is likely that some of these regions will not be replicated, but the smaller ones should not necessarily be rejected out of hand.

The genetics of VUR reflect the complexity of the development of the urinary tract. VUR results from poor function of the vesicoureteric valve. The development of the renal tract in the embryo begins with the formation of the ureteric bud, an outgrowth of the mesonephric (Wolffian) duct. ${ }^{8}$ Reciprocal signalling between the ureteric bud and the metanephrogenic mesenchyme stimulates the ureteric bud to grow to form the ureter and to branch to form the collecting ducts, and stimulates the metanephrogenic mesenchyme to form the kidney. The part of the mesonephric duct between the urogenital sinus and the newly developed ureter is removed by apoptosis, whereupon the freed end of the ureter inserts into the bladder wall and the vesicoureteric valve is formed. The precise position at which the UB grows out from the mesonephric duct is critical for the development of the whole urinary tract and many genes are involved in the control of this process. Aberrant or multiple ureteric budding can lead not only to VUR but to a range of abnormalities of the kidneys and urinary tract. This is at least partly because some of the same genes that are involved in ureteric budding are also involved in later stages of the process. Thus, mutation of any one of many genes can cause anomalies of the ureter and/or kidney, and VUR may be found in combination with such anomalies. It is possible that mutation of several of these genes may be responsible for isolated VUR, though the mutations may differ from those causing additional anomalies.

In view of this, it is not surprising that there is not very much difference between our two sets of results (with and without the families with duplex kidneys and other anomalies), confirming our opinion that these families do not represent a different genetic entity. It is also not surprising that studies of the genetics of VUR in humans have indicated heterogeneity, 22 2325262930 and that there has been disagreement between them. Even in a study such as ours, with a large number of families, genes in which mutations are only found in a small proportion of families may not be detected at traditionally accepted significance levels. Our results yielded a number of peaks in the HLOD/NPL topography, of which 15 are listed in the tables. However, the fact that many of these peaks are well below accepted levels of credence as potential loci of causative mutations does not indicate that they should immediately be 


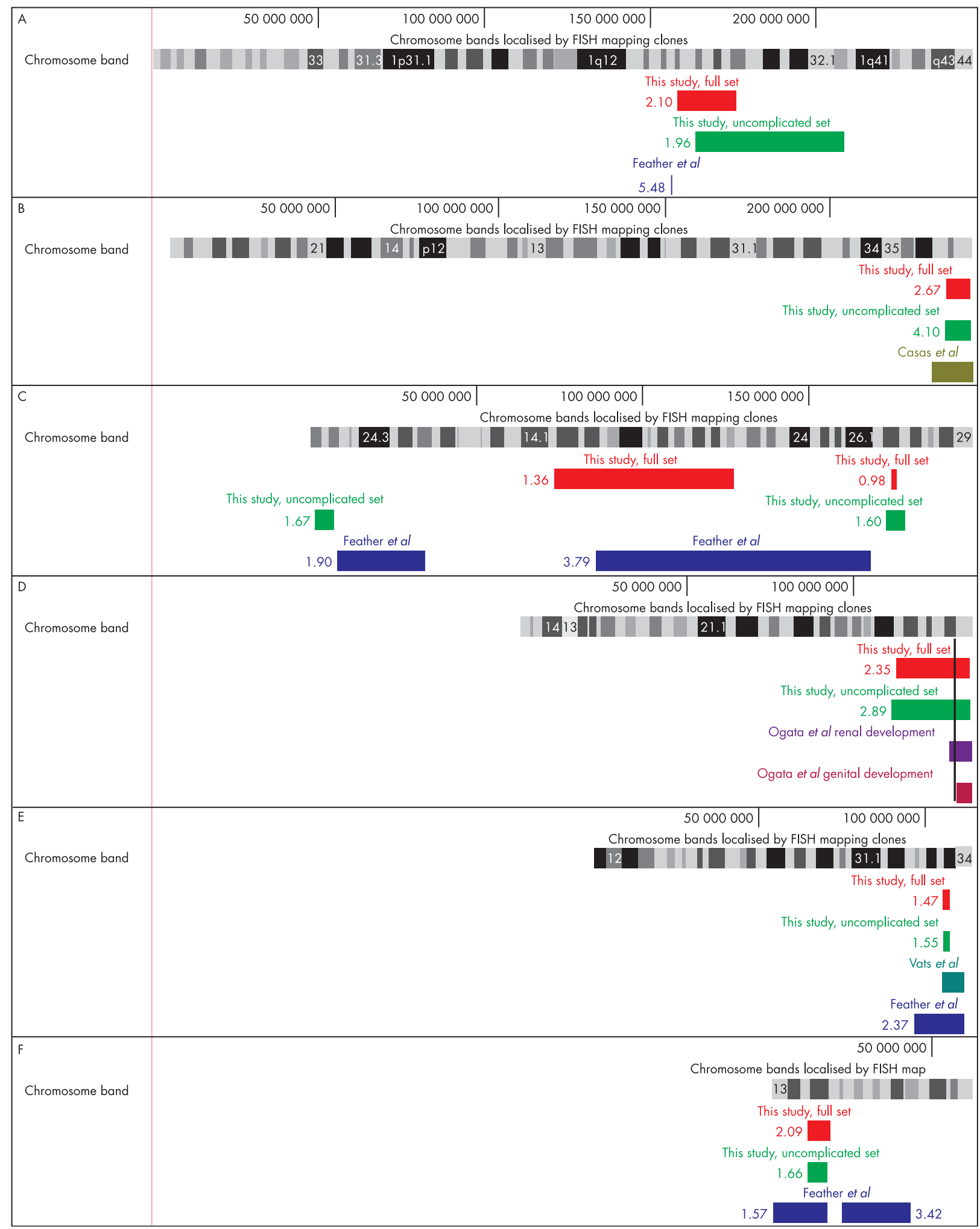

Figure 2 Comparison of regions suggestive of linkage in this study with those identified in other studies. (A) chromosome 1; (B) chromosome 2; (C) chromosome 3; (D) chromosome 10. The vertical line indicates the position of the peak in the uncomplicated set. (E) chromosome 13; (F) chromosome 20. Regions of suggestive evidence for linkage from the full set of families used in this study are shown in red; results from the uncomplicated set are shown in light green. Results from other studies are coded as follows: Feather et al, blue; Casas et al, brown; Ogata et al (renal development region), purple; Ogata et al (genital development region), maroon; Vats et al, aqua. The chromosomes are drawn to the scale of nucleotides rather than of their cytogenetic lengths.

ignored as artefacts; at least those that show agreement with results of earlier studies should be given further consideration.

Peaks in our study that coincided or overlapped with areas identified in other studies are illustrated in fig 2. A peak (NPL 1.47 in the full set, 1.55 in the uncomplicated set) in $13 \mathrm{q} 33$ coincides with a region identified by interstitial deletion mapping in children with renal anomalies, some of whom had VUR. ${ }^{26}$ Similarly, in a study of patients with terminal deletions of 10q26, a location at which we identified a peak NPL of 2.35 (full set) and 2.89 (uncomplicated set), all cases had 
either urinary-tract anomalies (including VUR), genital anomalies or both. ${ }^{25}$

The first genome scan for VUR ${ }^{22}$ studied seven extended families, whereas our study used 129 families, but ours were only nuclear families, thus it was essentially an affected siblingpair study. The other difference was that the first study used 375 microsatellite markers, which are highly variable, so that nearly all individuals are heterozygotes and therefore nearly all markers are informative in every family, whereas our study used $>10$ times as many markers, but they were SNPs with an average heterozygosity of $46 \%$, meaning that each marker will be uninformative in some families. However, SNPs in high density, such as those used here, can provide greater information content and better resolution, and may be less biased by genotyping error rates. ${ }^{44}{ }^{45}$ Nonetheless, there is good agreement between the two studies, with coincident or overlapping peaks on chromosomes 1, 3, 13 and 20 (fig 2). Furthermore, there has been a recent report of mosaic monosomy 20 in the renal tract of a child with bilateral VUR ${ }^{27}$ and the principal peak of the genome scan of Conte $e \mathrm{al}^{23}$ is on $3 \mathrm{q}$, although the exact region has yet to be published.

Our region of greatest significance is in the terminal band of chromosome 2, q37. We have searched the case reports of 77 cases of terminal deletions of $2 \mathrm{q}$ (mainly with breakpoints at 2q37, but a few more proximal), plus four unkaryotyped close relatives with similar phenotypes ${ }^{46-56}$ (see also Casas et al ${ }^{57}$ and references therein). Of these 81 cases, 7 were reported to have had urinary tract anomalies, ${ }^{48}{ }^{57-62} \mathrm{l}$ of whom was recorded to have bilateral VUR, ${ }^{59}$ and 3 cases without recorded anomalies were reported to have recurrent UTIs and therefore may also have had VUR. ${ }^{59}$ As this region is gene-rich, even small deletions tend to cause multiple anomalies, and VUR may have been under-reported. One of the candidates at the centre of our region is the transcription factor TWIST2, but the sequence of this human gene is unfortunately incomplete, as there are gaps in both the reference and Celera genome sequences in this region. Other possible candidates are the transcription factor HES6 and the integrin-linked kinase-associated serine/threonine phosphatase, ILKAP, which may participate in the wnt signalling pathway.

Thus we have detected in our families six regions supported by earlier studies, on 1q, 2q 3q, 10q, 13q and 20p (fig 2). However, others of similar significance, on chromosomes $6 \mathrm{q}$, $7 \mathrm{q}, 16 \mathrm{q}$ and $2 \mathrm{lq}$, have not been reported previously in genetic studies of VUR in humans (VUR has been reported to be linked to the HLA region on $6 \mathrm{p},{ }^{64}$ but we had no peak in this region).

Yeung et $a l^{65}$ concluded that mild reflux affects mostly females and a small proportion of males, whereas severe reflux with congenital renal malformation affects almost exclusively males, and our own data are in broad agreement. ${ }^{66}{ }^{67}$ It is therefore possible that the relative significances of different regions might be affected by the method of ascertainment of probands. Several studies of VUR have noted a preponderance of males (Yeung et $a l^{65}$ and references therein) whereas our series had more affected female patients. Our index cases were ascertained through UTIs, which, after the first year of life, are more common in female patients, and may therefore give more emphasis to genes causing mild VUR without renal anomalies than does ascertainment by other methods, such as detection of hydronephrosis on prenatal ultrasound.

The former conclusion that VUR is a homogeneous disorder $^{30}$ is no longer tenable; it is clearly heterogeneous. The subgroup of 25 families with additional phenotypic features was too small to analyse on its own. We expected that the removal of this subgroup would cause a reduction in the NPL scores of those regions that we had identified as containing loci associated with renal anomalies, on 2q37, 10q26, and 13q33, but in fact, all scores rose, particularly that on $2 \mathrm{q}$, and there were modest changes, up or down, to the NPL scores of other regions, with the exception of a new peak appearing on 17q. Thus, many of the genes represented by our peaks may be associated with VUR, with or without renal and ureteric anomalies, depending upon the mutation, hence the removal of the subgroup had a rather random effect, by changing the relative proportions of mutated loci left in the sample. Drastic changes in results, such as the appearance of the 17q peak, may have arisen due to fluctuations in the amount of evidence supporting and/or rejecting linkage in the underlying dataset, or due to random chance alone. Without corroborating or even suggestive evidence from additional studies, results such as this $17 \mathrm{q}$ peak require replication before any further investigation is warranted.

Our genome scan has revealed a number of large regions (mean intervals of 9.1 and $12.9 \mathrm{MB}$ in the full and uncomplicated sets, respectively) that, when combined together, provide a very large region for follow-up studies. In some regions, there are good candidate genes, but in others, it is much less obvious which gene might be the relevant one. There is almost nothing known about many of the genes revealed by the Human Genome Project, making it difficult to decide which genes to investigate, so that fine mapping is necessary in some regions. Similar genome scans on other groups of patients with VUR should provide valuable replication of these results and help eliminate false positive peaks. In the meantime, we shall be investigating the likely candidates. Our total number of families is now $>200$ and we have 600 DNA samples available from healthy Irish controls. These will be useful for investigation of which mutations are causative and which are normal polymorphisms, and possibly which common variants are associated with an increased risk of VUR or associated developmental anomalies. The recently published data on copy-number variation in the human genome ${ }^{68}$ will also be taken into account.

As we have said earlier, VUR results from developmental anomaly and can have serious consequences of hypertension and renal failure, yet in many cases it resolves spontaneously without any damage. VUR is clearly genetically heterogeneous, so genotyping will not provide a simple diagnostic test, but finding the genes will be the first step in the process of understanding the aetiology of the condition. It is to be hoped that it may be possible to identify which mutations are compatible with spontaneous resolution and whether any are related to inevitable renal damage, which will help with prognosis and genetic counselling, and in due course may lead to new forms of treatment.

\section{ACKNOWLEDGEMENTS}

This work was funded by grants from The Children's Medical and Research Foundation, Our Lady's Children's Hospital, Crumlin, Dublin 12, Ireland. We wish to thank Josephine Mulligan for her help with the clinical information and Sean Ennis for helpful advice.
Authors' affiliations
H Kelly, A J Green, D E Barton, The National Centre for Medical Genetics and University College Dublin Department of Medical Genetics, Our Lady's Children's Hospital, Crumlin, Dublin, Ireland
C Molony, Rosetta Inpharmatics, Seattle, Washington, USA
J Darlow, A Yoneda, The National Centre for Medical Genetics and The Children's Research Centre, Our Lady's Children's Hospital, Crumlin, Dublin, Ireland
P Puri, M Pirker, The Children's Research Centre, Our Lady's Children's Hospital, Crumlin, Dublin, Ireland
A Yoneda, The Children's Research Centre, Our Lady's Children's Hospital, Crumlin, Dublin, Ireland and Department of Paediatric Surgery, Osaka University Medical School, Osaka, Japan 
A J Green, D E Barton, The National Centre for Medical Genetics, Our Lady's Children's Hospital Crumlin, Dublin, Ireland, and Department of Medical Genetics and UCD Conway Institute for Biomolecular and Biomedical Research, National University of Ireland, Dublin P Puri, The Children's Research Centre, Our Lady's Children's Hospital Crumlin, Dublin, Ireland, and National Children's Hospital, Tallaght, Dublin, Ireland

Competing interests: None.

\section{REFERENCES}

1 Eccles MR, Jacobs GH. The genetics of primary vesico-ureteric reflux. Ann Acad Med Singapore 2000;29h:337-45.

2 Eccles MR, Bailey RR, Abbott GD, Sullivan MJ. Unravelling the genetics of vesicoureteric reflux: a common familial disorder. Hum Mol Genet 1996:5:1425-9.

3 Devriendt K, Groenen P, Van Esch H, van Dijck M, Van de Ven W, Fryns JP, Proesmans W. Vesico-ureteral reflux: a genetic condition? Eur J Pediatr 1998; 157:265-71.

4 Chertin B, Puri P. Familial vesicoureteral reflux. J Urol 2003;169:1804-8.

5 Krzemien G, Roszkowska-Blaim M, Kostro I, Szmigielska A, Madzik J. (Vesicoureteral reflux in children with prenatal suspicion of urinary tract abnormalities). Przegl Lek 2006;63(Suppl):127-30.

6 Siomou E, Papadopoulou F, Kollios KD, Photopoulos A, Evagelidou E, Androulakakis P, Siamopoulou A. Duplex collecting system diagnosed during the first 6 years of life after a first urinary tract infection: a study of 63 children. J Urol, 2006;175:678-81; discussion 81-2..

7 Seseke F, Strauss A, Seseke S, Zappel H, Ringert RH, Zoller G. (Long-term experience with Cohen ureteral reimplantation in bilateral vesicoureteral reflux in childhood). Urologe A 2006;45:852-7.

8 Ichikawa I, Kuwayama F, Pope JCt, Stephens FD, Miyazaki Y. Paradigm shift from classic anatomic theories to contemporary cell biological views of CAKUT. Kidney Int 2002;61:889-98

9 Murawski IJ, Gupta IR. Vesicoureteric reflux and renal malformations: a developmental problem. Clin Genet 2006;69:105-17.

10 Hu P, Deng FM, Liang FX, Hu CM, Auerbach AB, Shapiro E, Wu XR, Kachar B, Sun TT. Ablation of uroplakin III gene results in small urothelial plaques, urothelial leakage, and vesicoureteral reflux. J Cell Biol 2000;151:961-72.

11 Kelly H, Ennis S, Yoneda A, Bermingham C, Shields DC, Molony C, Green AJ, Puri $P$, Barton DE. Uroplakin III is not a major candidate gene for primary vesicoureteral reflux. Eur J Hum Genet 2005;13:500-2.

12 Giltay JC, van de Meerakker J, van Amstel HK, de Jong TP. No pathogenic mutations in the uroplakin III gene of 25 patients with primary vesicoureteral reflux. J Urol 2004;171:931-2.

13 Jiang S, Gitlin J, Deng FM, Liang FX, Lee A, Atala A, Baver SB, Ehrlich GD Feather SA, Goldberg JD, Goodship JA, Goodship TH, Hermanns M, Hu FZ, Jones KE, Malcolm S, Mendelsohn C, Preston RA, Retik AB, Schneck FX, Wright V, Ye XY, Woolf AS, Wu XR, Ostrer H, Shapiro E, Yu J, Sun T. Lack of major involvement of human uroplakin genes in vesicoureteral reflux: implications for disease heterogeneity. Kidney Int 2004;66:10-19.

14 Jenkins D, Bitner-Glindzicz M, Malcolm S, Allison J, de Bruyn R, Flanagan S, Thomas DF, Belk RA, Feather SA, Bingham C, Southgate J, Woolf AS. Mutation analyses of Uroplakin II in children with renal tract malformations. Nephrol Dial Transplant 2006;21:3415-21.

15 Jenkins D, Bitner-Glindzicz M, Malcolm S, Hu CC, Allison J, Winyard PJ, Gullett AM, Thomas DF, Belk RA, Feather SA, Sun TT, Woolf AS. De novo uroplakin Illa heterozygous mutations cause human renal adysplasia leading to severe kidney failure. J Am Soc Nephrol 2005;16:2141-9.

16 Schonfelder EM, Knuppel T, Tasic V, Miljkovic P, Konrad M, Wuhl E, Antignac C, Bakkaloglu A, Schaefer F, Weber S. Mutations in uroplakin IIIA are a rare cause of renal hypodysplasia in humans. Am J Kidney Dis 2006;47:1004-12.

17 Sanyanusin P, McNoe LA, Sullivan MJ, Weaver RG, Eccles MR. Mutation of PAX2 in two siblings with renal-coloboma syndrome. Hum Mol Genet 1995;4:2183-4.

18 Sanyanusin P, Schimmenti LA, McNoe LA, Ward TA, Pierpont ME, Sullivan MJ, Dobyns WB, Eccles MR. Mutation of the PAX2 gene in a family with optic nerve colobomas, renal anomalies and vesicoureteral reflux. Nat Genet 1995:9:358-64.

19 Nishimoto K, lijima K, Shirakawa T, Kitagawa K, Satomura K, Nakamura H, Yoshikawa N. PAX2 gene mutation in a family with isolated renal hypoplasia. $J$ Am Soc Nephrol 2001;12:1769-72.

20 Choi KL, McNoe LA, French MC, Guilford PJ, Eccles MR. Absence of PAX2 gene mutations in patients with primary familial vesicoureteric reflux. J Med Genet 1998;35:338-9.

21 Lu W, van Eerde AM, Fan X, Quintero-Rivera F, Kulkarni S, Ferguson H, Kim HG, Fan Y, Xi Q, Li QG, Sanlaville D, Andrews W, Sundaresan V, Bi W, Yan J, Giltay JC, Wiimenga C, de Jong TP, Feather SA, Woolf AS, Rao Y, Lupski JR, Eccles MR, Quade BJ, Gusella JF, Morton CC, Maas RL. Disruption of ROBO2 is associated with urinary tract anomalies and confers risk of vesicoureteral reflux. Am J Hum Genet 2007;80:616-32.

22 Feather SA, Malcolm S, Woolf AS, Wright V, Blaydon D, Reid CJ, Flinter FA, Proesmans W, Devriendt K, Carter J, Warwicker P, Goodship TH, Goodship JA Primary, nonsyndromic vesicoureteric reflux and its nephropathy is genetically heterogeneous, with a locus on chromosome 1. Am J Hum Genet 2000;66:1420-5
23 Conte ML, Bertoli-Avella AM, de Graaf BM, Lama G, La Manna A, Rambaldi PF Oostra BA, Perrotta S. A novel locus for primary familial vesicoureteral reflux maps to chromosome 3q. Eur J Hum Genet 2006;14(Suppl):335.

24 Groenen PM, Vanderlinden G, Devriendt K, Fryns JP, Van de Ven WJ. Rearrangement of the human CDC5L gene by a $+(6 ; 19)(p 21 ; q 13.1)$ in a patient with multicystic renal dysplasia. Genomics 1998:49:218-29.

25 Ogata T, Muroya K, Sasagawa I, Kosho T, Wakui K, Sakazume S, Ito K, Matsuo N, Ohashi H, Nagai T. Genetic evidence for a novel gene(s) involved in urogenital development on 10q26. Kidney Int 2000;58:2281-90.

26 Vats KR, Ishwad C, Singla I, Vats A, Ferrell R, Ellis D, Moritz M, Surti U, Jayakar P, Frederick DR, Vats AN. A locus for renal malformations including vesico-ureteric reflux on chromosome 13q33-34. J Am Soc Nephrol 2006;17:1158-67.

27 Stefanou EG, Crocker M, Boon A, Stewart H. Cryptic mosaicism for monosomy 20 identified in renal tract cells. Clin Genet 2006;70:228-32.

28 Yoneda A, Cascio S, Green A, Barton D, Puri P. Angiotensin II type 2 receptor gene is not responsible for familial vesicoureteral reflux. J Urol 2002;168: 1138-41.

29 Sanna-Cherchi S, Reese A, Hensle T, Caridi G, Izzi C, Kim YY, Konka A, Murer L, Scolari F, Ravazzolo R, Ghiggeri GM, Gharavi AG. Familial vesicoureteral reflux: testing replication of linkage in seven new multigenerational kindreds. J Am Soc Nephrol 2005:ASN.2004121034.

30 van Eerde AM, Koelman BPC, van de Kamp JM, de Jong TPVM, Wijmenga C Giltay JC. Linkage study in four large Dutch families with VUR: exclusion of a previously reported locus and (separate) candidate genes. Eur J Hum Genet 2006;14(Suppl):334.

31 Decter RM. Update on vesicoureteral reflux: pathogenesis, nephropathy, and management. Rev Urol 2001;3:172-8.

32 Greenbaum LA, Mesrobian HG. Vesicoureteral reflux. Pediatr Clin North Am 2006:53:413-27.

33 Orellana P, Pizarro ME, Garcia F, Baquedano P. Daño renal en reflujo vesicoureteral asociado a doble sistema pieloureteral (Renal damage in vesicoureteric reflux associated with duplex pyeloureteric systems). Rev Esp Med Nucl 2005;24:387-91.

34 Abecasis GR, Wigginton JE. Handling marker-marker linkage disequilibrium: pedigree analysis with clustered markers. Am J Hum Genet 2005;77:754-67.

35 Abecasis GR, Cherny SS, Cookson WO, Cardon LR. Merlin-rapid analysis of dense genetic maps using sparse gene flow trees. Nat Genet 2002;30:97-101

36 Whittemore AS, Halpern J. A class of tests for linkage using affected pedigree members. Biometrics 1994;50:118-27.

37 Kong A, Cox NJ. Allele-sharing models: LOD scores and accurate linkage tests Am J Hum Genet 1997;61:1179-88.

38 Mukhopadhyay N, Almasy L, Schroeder M, Mulvihill WP, Weeks DE. Mega2: data-handling for facilitating genetic linkage and association analyses. Bioinformatics 2005;21:2556-7.

39 Webb EL, Sellick GS, Houlston RS. SNPLINK: multipoint linkage analysis of densely distributed SNP data incorporating automated linkage disequilibrium removal. Bioinformatics 2005;21:3060-1.

40 Chapman CJ, Bailey RR, Janus ED, Abbott GD, Lynn KL. Vesicoureteric reflux: segregation analysis. Am J Med Genet 1985:20:577-84

41 Abreu PC, Hodge SE, Greenberg DA. Quantification of type I error probabilities for heterogeneity LOD scores. Genet Epidemiol 2002;22:156-69.

42 Lander E, Kruglyak L. Genetic dissection of complex traits: guidelines for interpreting and reporting linkage results. Nature Genetics 1995;11:241-7.

43 Abecasis GR, Cookson WO, Cardon LR. Pedigree tests of transmission disequilibrium. Eur J Hum Genet 2000;8:545-51

44 Nsengimana J, Renard H, Goldgar D. Linkage analysis of complex diseases using microsatellites and single-nucleotide polymorphisms: application to alcoholism. BMC Genet 2005;6(Suppl):S10.

45 Schaid DJ, Guenther JC, Christensen GB, Hebbring S, Rosenow C, Hilker CA, McDonnell SK, Cunningham JM, Slager SL, Blute ML, Thibodeau SN. Comparison of microsatellites versus single-nucleotide polymorphisms in a genome linkage screen for prostate cancer-susceptibility loci. Am J Hum Genet 2004;75:948-65.

46 Alkuraya FS, Kimonis VE, Holt L, Murata-Collins JL. A patient with a ring chromosome 2 and microdeletion of $2 q$ detected using FISH: Further support for "ring chromosome 2 syndrome". Am J Med Genet A 2005; 132:447-9.

47 Armstrong L, Allanson JE, Weaver DD, Bevan CJ, Hobart HH. Unrelated patients with a rearrangement of chromosome 2 causing duplication of 2 p23 and deletion of 2q37. Am J Med Genet A 2005;134:299-304.

48 Bacino CA, Kashork CD, Davino NA, Shaffer LG. Detection of a cryptic translocation in a family with mental retardation using FISH and telomere regionspecific probes. Am J Med Genet 2000;92:250-5.

49 Bruyere H, Rajcan-Separovic E, Doyle J, Pantzar T, Langlois S. Familial cryptic translocation $(2 ; 17)$ ascertained through recurrent spontaneous abortions. Am J Med Genet A 2003; 123:285-9.

50 Caliskan MO, Karauzum SB, Mihci E, Tacoy S, Luleci G. Subtelomeric chromosomal rearrangements detected in patients with idiopathic mental retardation and dysmorphic features. Genet Couns 2005;16:129-38.

51 Chassaing N, De Mas P, Tauber M, Vincent MC, Julia S, Bourrouillou G, Calvas $P$, Bieth E. Molecular characterization of a cryptic $2 q 37$ deletion in a patient with Albright hereditary osteodystrophy-like phenotype. Am J Med Genet A 2004; 128:410-13.

52 Giardino D, Finelli P, Gottardi G, Clerici D, Mosca F, Briscioli V, Larizza L. Cryptic subtelomeric translocation $t(2 ; 16)(q 37 ; q 24)$ segregating in a family with unexplained stillbirths and a dysmorphic, slightly retarded child. Eur J Hum Genet 2001;9:881-6.

53 Giardino D, Finelli P, Gottardi G, De Canal G, Della Monica M, Lonardo F, Scarano G, Larizza L. Narrowing the candidate region of Albright hereditary 
osteodystrophy-like syndrome by deletion mapping in a patient with an unbalanced cryptic translocation $t(2 ; 6)(q 37.3 ; q 26)$. Am J Med Genet A 2003;122:261-5

54 Lukusa T, Smeets E, Vogels A, Vermeesch JR, Fryns JP. Terminal 2q37 deletion and autistic behaviour. Genet Couns 2005;16:179-80.

55 Lukusa T, Vermeesch JR, Holvoet M, Fryns JP, Devriendt K. Deletion 2q37.3 and autism: molecular cytogenetic mapping of the candidate region for autistic disorder. Genet Couns 2004; 15:293-301.

56 Shrimpton AE, Braddock BR, Thomson LL, Stein CK, Hoo JJ. Molecular delineation of deletions on $2 q 37.3$ in three cases with an Albright hereditary osteodystrophy-like phenotype. Clin Genet 2004;66:537-44.

57 Casas KA, Mononen TK, Mikail CN, Hassed SJ, Li S, Mulvihill JJ, Lin HJ, Falk RE. Chromosome 2q terminal deletion: report of 6 new patients and review of phenotypebreakpoint correlations in 66 individuals. Am J Med Genet A 2004;130:331-9.

58 Wang TH, Johnston K, Hsieh CL, Dennery PA. Terminal deletion of the long arm of chromosome 2 in a premature infant with karyotype: $46, X Y$,del(2)(q37). Am J Med Genet 1994;49:399-401.

59 Batstone PJ, Simpson S, Bonthron DT, Keng WT, Hamilton D, Forsyth L, Sales M, Pratt N, Goudie D. Effective monosomy or trisomy of chromosome band $2 q 37.3$ due to the unbalanced segregation of a 2;11 translocation. Am J Med Genet $A$ 2003;118:241-6

60 Viot-Szoboszlai G, Amiel J, Doz F, Prieur M, Couturier J, Zucker JN, Henry I, Munnich A, Vekemans M, Lyonnet S. Wilms' tumor and gonadal dysgenesis in a child with the 2q37.1 deletion syndrome. Clin Genet 1998;53:278-80.

61 Reddy KS, Flannery D, Farrer RJ. Microdeletion of chromosome sub-band 2q37.3 in two patients with abnormal situs viscerum. Am J Med Genet 1999;84:460-8.
62 Waters BL, Allen EF, Gibson PC, Johnston T. Autopsy findings in a severely affected infant with a $2 q$ terminal deletion. Am J Med Genet 1993:47:1099-103.

63 Bijlsma EK, Aalfs CM, Sluitier S, Oude Luttikhuis ME, Trembath RC, Hoovers JM, Hennekam RC. Familial cryptic translocation between chromosomes 2 qter and 8qter: further delineation of the Albright hereditary osteodystrophy-like phenotype. J Med Genet 1999;36:604-9.

64 Macintosh M, Almarhoos G, Heath DA. HLA linkage with familial vesicoureteral reflux and pelviureteric junction obstruction. Tissue Antigens 1989;34:185-9.

65 Yeung CK, Godley ML, Dhillon HK, Gordon I, Duffy PG, Ransley PG. The characteristics of primary vesico-ureteric reflux in male and female infants with pre-natal hydronephrosis. Br J Urol 1997;80:319-27.

66 Pirker ME, Colhoun E, Puri P. Renal scarring in familial vesicoureteral reflux: Is prevention possible? J Urol 2006;176(Suppl): 1842-6.

67 Pirker ME, Mohanan N, Colhoun E, Barton D, Green A, Puri P. Familial vesicoureteral reflux: Influence of sex on prevalence and expression. J Urol 2006;176(Suppl): 1776-80.

68 Redon R, Ishikawa S, Fitch KR, Feuk L, Perry GH, Andrews TD, Fiegler H, Shapero MH, Carson AR, Chen W, Cho EK, Dallaire S, Freeman JL, Gonzalez JR, Gratacos M, Huang J, Kalaitzopoulos D, Komura D, MacDonald JR, Marshall CR Mei R, Montgomery L, Nishimura K, Okamura K, Shen F, Somerville MJ, Tchinda J, Valsesia A, Woodwark C, Yang F, Zhang J, Zerjal T, Zhang J, Armengol L, Conrad DF, Estivill X, Tyler-Smith C, Carter NP, Aburatani H, Lee C Jones KW, Scherer SW, Hurles ME. Global variation in copy number in the human genome. Nature 2006;444:444-54. 